\title{
Sporcularda peroneal tendon sorunları
}

\section{Peroneal tendon problems in sports}

\author{
Osman Civan ${ }^{1}$, Mustafa Ürgüden² \\ ${ }^{1} Y u ̈ k s e k o v a$ Devlet Hastanesi Ortopedi ve Travmatoloji Kliniği, Hakkari \\ ${ }^{2}$ Akdeniz Üniversitesi Tıp Fakültesi Ortopedi ve Travmatoloji Anabilim Dalı, Antalya
}

\begin{abstract}
Peroneal tendon yaralanmaları sıktır ve tanı konulma sıklığı özellikle sporcularda giderek artış göstermektedir. Peroneal tendon yaralanmaları sıklıkla lateral ayak bileği burkulması olarak yanlış tanı alır ve tedavi yanlış uygulanır. Bu yanlış tedavi nedeniyle, akut dönemde kolaylıkla konservatif olarak tedavi edilebilecek bir patoloji kronik dönemde cerrahi gerektirebilir.
\end{abstract}

Ayak bileği burkulması sonrası inatçı lateral ayak bileği ağrısı olan hastalarda peroneal tendon yaralanmasından kuşku duyulmalı ve ilgili tetkikler yapılmalıdır. Çoğu hastaya kronik dönemde tanı konuluyor olsa da, peroneus brevisin akut yırtığı ve daha az sıklıkta görülen peroneus longusun akut yırtığı gibi patolojilerin olabileceğini akılda tutmak, tanı koymak için çok önemlidir.

Peroneal tendon yaralanmalarıyla ilişkili olan peroneal subluksasyon ve peroneal dislokasyon gibi patolojiler, hem akut hem de kronik dönemde karşılaşılabilecek diğer peroneal tendon patolojileridir. Peroneal tendon dislokasyonu sıklıkla spor yaralanmalarını takiben, özellikle kayak sonrası meydana gelir. Aynı zamanda buz pateni, futbol, basketbol, rubgy ve jimnastik sonrası da sıklıkla görülür.

Peroneus longus ve peroneus brevis tendonlarının konservatif tedavisi benzerdir. İstirahat, immobilizasyon, kriyoterapi ve non-steroidal anti-inflamatuvar ilaçlar yaralanmanın akut evrelerinde etkin tedavi şeklidir. Ancak konservatif tedavi olguların \%20'sinde başarılıdır ve geri kalan \%80'lik hasta grubunda cerrahi tedavi gerekli olacaktır. Subluksasyon ya da dislokasyonun konservatif tedavisinde, ayağın peroneal tendonlarını redükte pozisyona getiren, plantar fleksiyon ve inversiyon pozisyonunda altı haftalık kısa bacak alçısı uygulanabilir. Cerrahi tedavisinde; superior peroneal retinakulumun (SPR) direkt onarımı, SPR'nin rekonstrüksiyonu, tendon re-routing prosedürleri, kemik bloğu prosedürleri ve oluk derinleştirme operasyonları uygulanabilir.

Anahtar sözcükler: peroneal tendon; peroneal tendon sorunları; sporcularda peroneal tendon sorunları; peroneal tendon yırtıkları
Peroneal tendon injuries are common, and the frequency of diagnosis is gradually increasing especially in athletes. Peroneal tendon injuries are commonly misdiagnosed as lateral ankle sprain, and treated wrongly. A pathology that could be treated easily in acute period would need surgery in chronic period because of this wrong treatment.

Peroneal tendon injuries should be suspected and related investigations should be done in patients have persistent lateral ankle pain after ankle sprain history. Even if most of the patients get diagnosis in the chronic period, it is very important to keep in mind that acute tear of peroneus brevis and the less common peroneus longus tear should not be ignored.

Pathologies like peroneal subluxation and peroneal dislocation that are associated with peroneal tendon injuries are the other peroneal tendon pathologies which could be seen in both acute and chronic periods. Peroneal tendon dislocations usually occur after sports injuries, especially after skiing. Also, it usually occurs after ice skating, football, basketball, rugby, and gymnastics.

Conservative treatment of peroneus longus and brevis are similar. Rest, immobilization, cryotherapy and nonsteroidal anti-inflammatory drugs are effective treatments in acute period of injury. But conservative treatment is successful at $20 \%$ of cases and the rest ( $80 \%)$ will need surgical treatment. Short leg cast that keeps foot in plantar flexion and inversion to reduce peroneals should be performed for 6 weeks for conservative treatment of subluxation and dislocation. In surgical treatment; directly repair of superior peroneal retinaculum (SPR), reconstruction of SPR, tendon re-routing, bone block, and groove deepening procedures can be used.

Key words: peroneal tendon; peroneal tendon disorders; peroneal tendon problems in sports; peroneal tendon tears

- Illetişim adresi: Dr. Mustafa Ürgüden, Akdeniz Üniversitesi Tıp Fakültesi Ortopedi ve Travmatoloji Anabilim Dalı, Antalya Tel: 0505 - 7598965 e-posta: urguden@akdeniz.edu.tr

- Geliș tarihi: 1 Ocak $2018 \quad$ Kabul tarihi: 1 Ocak 2018 


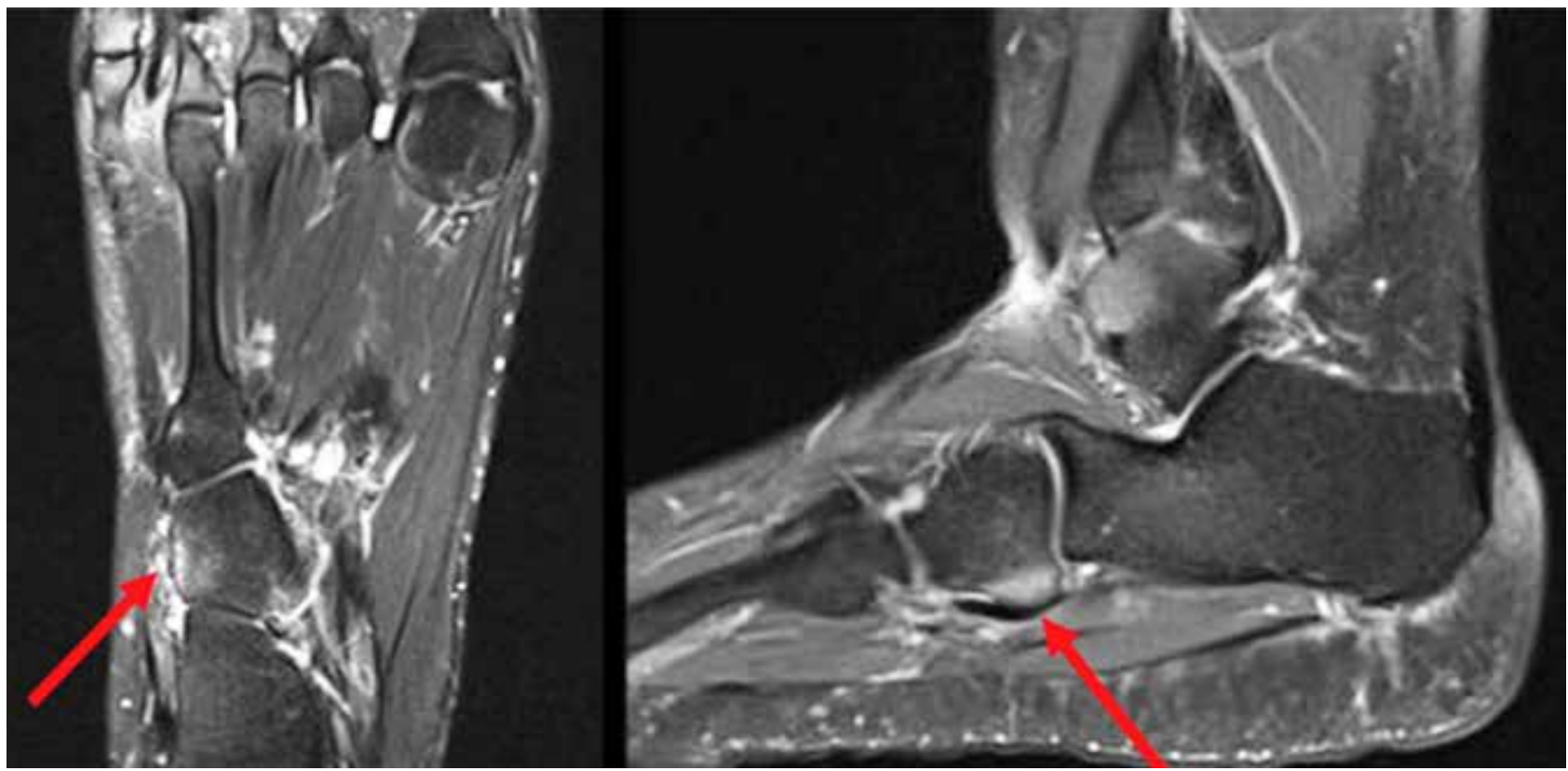

Şekil 1. Küboid noç çevresinde peroneus longus tenosinoviti, küboid kemikte ödem.

\section{ANATOMI ve BIYOMEKANIK}

Peroneus longus ve brevis kasları, krurisin lateral kompartmanında bulunur. Peroneus longus fibulanın proksimal 2/3'ünden, fibula başından, intermusküler septumdan ve tibianın lateral kondilinden köken alarak, distalde 1. metatarsın bazisinin lateral kenarına ve mediyal kuneiforma yapışır. Peroneus brevis ise fibulanın 2/3 distalinden ve intermusküler septumdan köken alarak 5. metatars bazisindeki stiloid çıkıntıya yapışır.

Peroneus longus ve brevisin her ikisi de yüzeyel peroneal sinir tarafindan innerve edilir. Tendonlara kan desteği, her iki tendona posterolateralden bağlanan vinkulayı besleyen posterior peroneal arter tarafindan sağlanır. Bir kadavra çalışmasında, peroneal tendonların seyri boyunca üç adet hipovasküler bölge olduğu gösterilmiştir. Peroneus brevis için lateral malleolün hemen arkasındaki fibular oluk 1. hipovasküler alandır. Peroneus longus içinse iki adet iskemik bölge vardır: birincisi fibulanın inferiorunda, tendonun peroneal tüberkülü geçtiği nokta; ikincisi ise peroneus longusun küboid çentiğin altından keskin bir şekilde geçtiği yerdir. Bu üç bölge, yırtıkların en sık görüldüğü bölgelerdir (Şekil 1). ${ }^{[1]}$

Her iki tendon, fibula tipinden $2,5-3,5 \mathrm{~cm}$ proksimale kadar uzanan ortak bir kılıfı paylaşır. Peroneus brevis tendonu, basık, ovoid bir şekle sahiptir ve lateral malleolün posterior köşesine doğru uzanır. Daha yuvarlak şekilli peroneus longus ise peroneus brevisin posterioruna doğru uzanarak, onu fibulanın arkasına doğru iter. Tendonların bu şekilde üst üste binmesinden dolayı ciddi bir mekanik basınç oluşur. Bu durum, zamanla peroneus breviste yırtık oluşmasına neden olabilir. ${ }^{[2]}$ Fibula tipinin hemen distalinde her iki tendon anteriora, peroneal tüberküle doğru ilk dönüşlerini yapar.

Peroneus brevis, peroneal tüberkülün hemen bitişiğinde üstüne doğru, peroneus longus ise inferioruna doğru yol alır. Peroneal tüberkül seviyesinde, her iki tendon da kendine ait tendon kılıfı ile ayrılarak yola devam eder. Peroneus brevis distale devam ederek 5. metatarsın bazisine yapışır. Peroneus longus ise peroneal tüberkülün hemen inferomediyalinde ikinci bir dönüş yaparak küboid çentiğe doğru yol alır ve burada oblik bir şekilde 3. dönüşünü yapıp, orta ayağın altından plantar peroneal tünel adında başka bir sinoviyal kılıf içinde 1 . metatars bazisine yapışmak üzere yol alır. ${ }^{[2]}$

Peroneal tendonların retrofibular oluğun içinde kalmasını sağlayan iki anatomik yapı vardır. Birisi fibulanın posterolateral yüzünden kalkaneusun lateral duvarına ve Aşil tendon kılıfına kadar uzanan güçlü fasyal bant olan superior peroneal retinakulumdur (SPR). Fibula tipinin $2 \mathrm{~cm}$ üstünden başlayan bu bağ, peroneal tendonları retrofibular olukta tutar. Fibula distali boyunca posterolateralde yer alan fibrokartilajinöz çıkıntı ise 2. stabilizördür. Bu çıkıntı, retrofibular oluğu 2 ile $4 \mathrm{~mm}$ arasında derinleştirir ve laterale doğru periost 


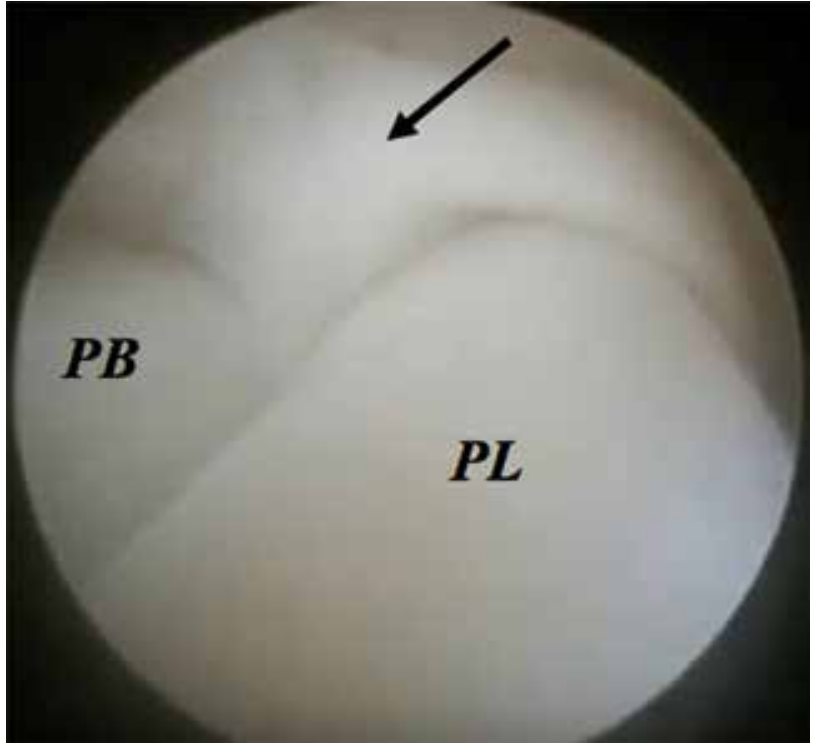

Şekil 2. Her iki peroneal tendon ve inferior peroneal retinakulumun endoskopik görüntüsü. $\mathrm{PL}$, peroneus longus; $\mathrm{PB}$, peroneus brevis ( $o k$, inferior peroneal retinakulum).

ile kaynaşır; tendonların subluksasyonunu önleyici olarak görev yapar. Inferior peroneal retinakulum ise inferior peroneal tüneli oluşturur ve kalkaneusun troklear çıkıntı seviyesindedir. İnferior peroneal retinakulum iki ayrı tünel olarak devam eder (Şekil 2).
Peroneus longus ve brevis kaslarının her ikisi de ayağın plantar fleksiyonu ve eversiyonunda görev alır. Arka ayağın total eversiyon gücünün $\% 28$ 'ini peroneus brevis sağlarken, peroneus longus \%35'ini sağlar. Peroneus brevis ön ayağın primer abduktorudur ve bu yüzden posterior tibial tendonun antagonisti olarak çalışır. Peroneus longus ise 1. ray'in plantar fleksiyonunda görev alır ve anterior tibial tendonun antagonisti olarak çalışır. Peroneal kas grubu ayak bileği inversiyon yaralanmalarının dinamik sekonder stabilizörüdür; uygun bir şekilde çalıştırıldığında, bir yırtığı ya da gerilmiş bir lateral bağ kompleksini kompanse edebilir. Her iki kas grubu da yürümenin basma fazında primer olarak aktiftir.[3]

\section{ANATOMIK VARYASYONLAR}

Distale uzanan peroneus brevis kası, tek başına \%33'e kadar varan oranlarda görülebilir (Şekil 3). Kasın şişliği SPR'nin superior kenarına kadar uzandığında tanı konur. Fakat distale uzanan peroneus brevis kasının neye bağlı olduğu konusu net değildir.

Muskülotendinöz bileşkenin ayak pozisyonuyla etkilenmesiyle ilişkilendirilmiştir. Asemptomatik gönüllü grupta, ayağın dorsifleksiyonu ile kasın oluğa uzandığı ve bunun ayağın plantar fleksiyonunda daha az sıklıkta görüldüğü bildirilmiştir. ${ }^{[4]}$ Bu nedenle, ayak bileği manyetik rezonans (MR) incelemelerinde ipuçlarını kaçırmamak ve tanıyı atlamamak için dikkatli olunmalıdır.

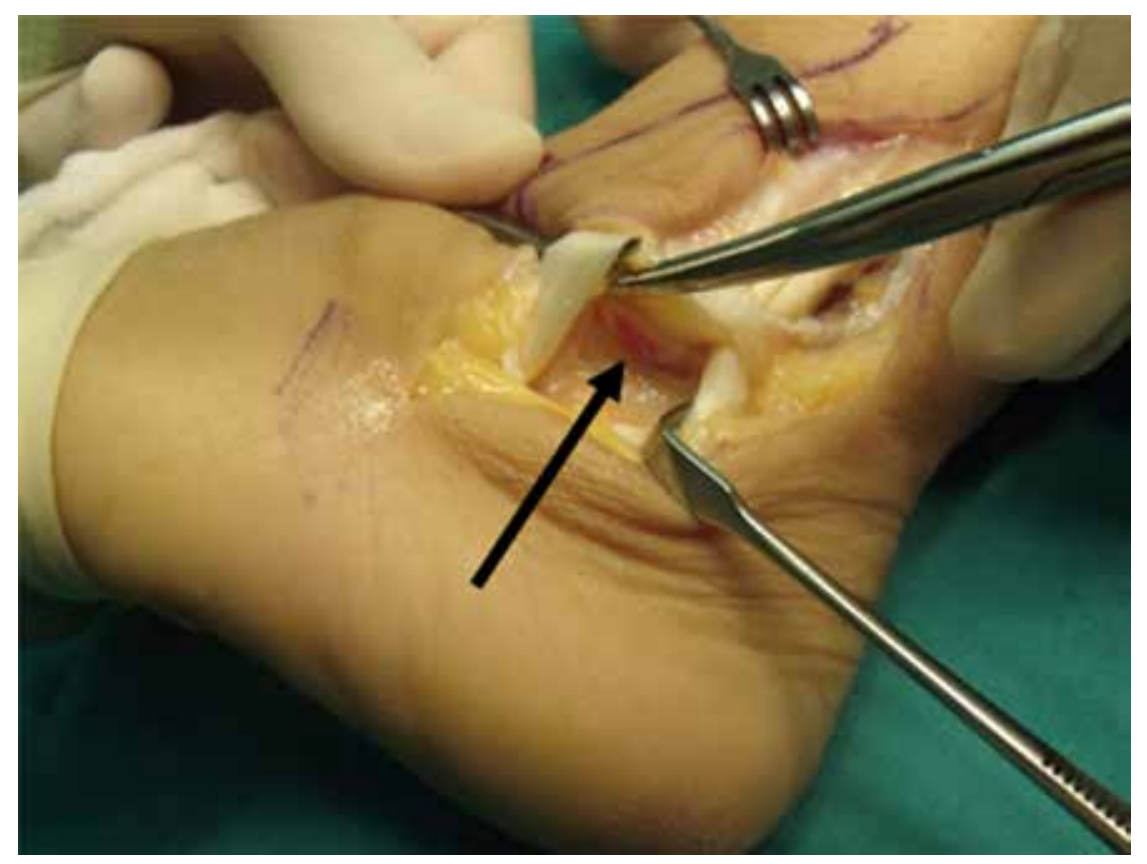

Şekil 3. Distale uzanan peroneus brevis kası (siyah ok). 


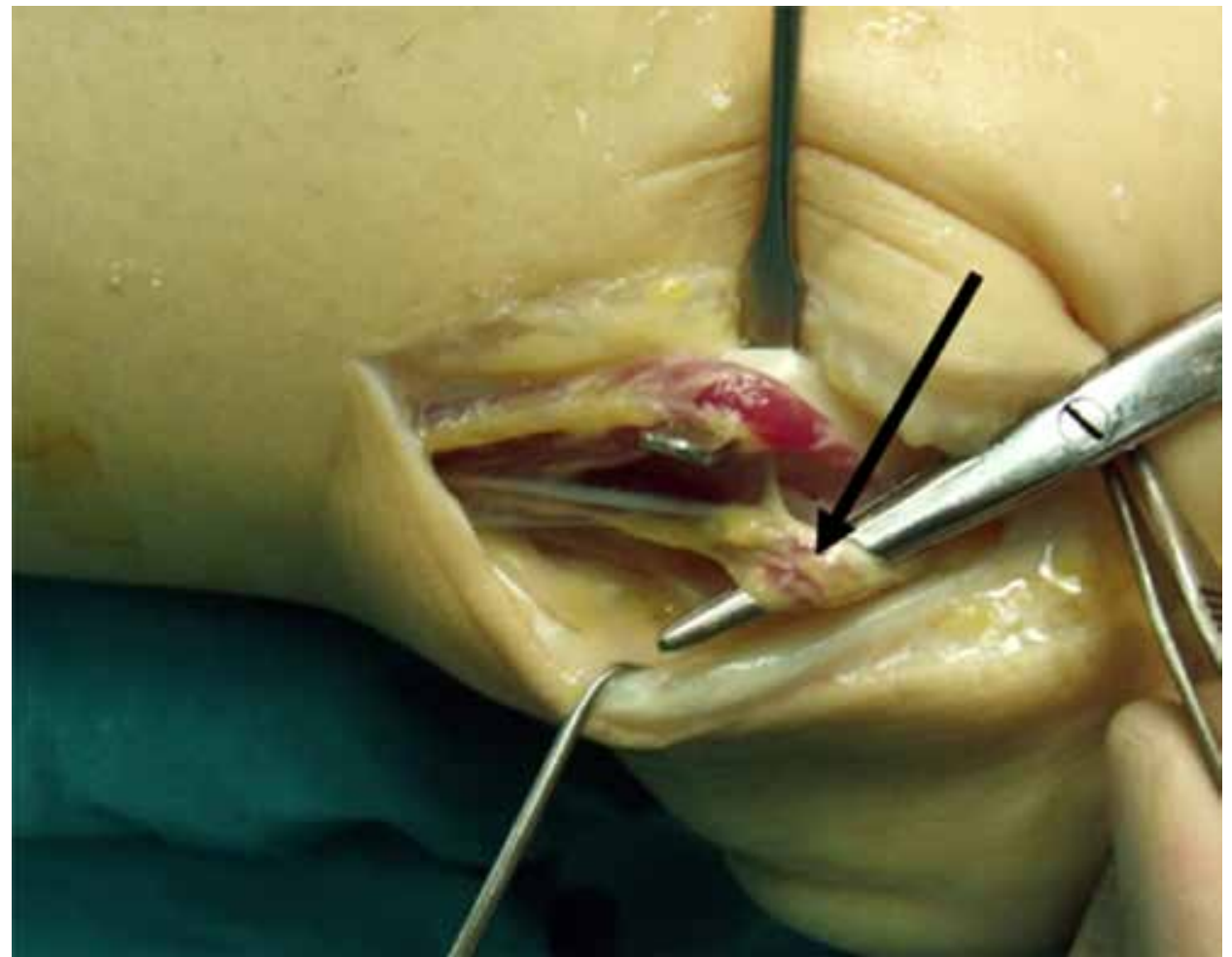

Şekil 4. Peroneus kuartus kası (siyah ok).

Peroneus kuartus kası (Şekil 4) tipik olarak peroneus brevis kasının göbek kısmından, krurisin distal 1/3'ünden köken alır ve peroneal tendonların posteromediyaline doğru inerek devam eder.

Yapışma yeri çeşitlilik gösterir ve en sık kalkaneusun retrotroklear eminensiasına ya da ara sıra 5. metatars bazisine, peroneus longus ya da brevis tendonlarına, inferiora ekstansör retinakuluma ya da küboid kemiğe yapışabilir. ${ }^{[5]}$ Kasın görülme sıklığı, kadavra çalışmalarında \%5,2 ile \%21,7 arasında değişen oranlarda bildirilmiştir. ${ }^{[5-7]}$

\section{ÖYKÜ VE FiZiK MUAYENE}

Öykü ve fizik muayenenin doğru yapılması, peroneal tendon yaralanmalarında doğru teşhisin konulmasındaki en önemli unsurlardan biridir. Akut yaralanmalar sıklıkla çözümlenememiş ayak bileği burkulması şeklinde tanımlanır, fakat kronik olgular "ayak bileği inversiyonu travması sonrasında gelişen lateral ayak bileği instabilitesi" şeklinde gelişir. ${ }^{[8]}$

Hastalarda; şişlik, hassasiyet, boşluk - boşa çıkma hissi, ve lateral ayak bileği instabilitesine ait şikayetler dışında, tipik olarak lateral ayak bileği ağrısı ve peroneal tendonlar boyunca uzanım gösteren ağrı olur. Fizik muayenede tendinopati ile yırtık ayrımını yapabilmek oldukça zordur; nitekim, tendon yırtığı daha az ağrı ile fakat daha çok güç kaybı ve şişlikle karşımıza çıkabilir. Dislokasyon olması durumunda ise hasta atlama hissi tarif eder.

Fizik muayene bulguları arasında, krepitasyon, şişlik ve peroneal tendon seyri boyunca ağrı yer alır. Ayağın aktif dorsifleksiyonu ve plantar fleksiyon-inversiyonuyla, ağrıda artış saptanır. Yırtık olması durumunda, ağrıda artış ile provokasyon testlerine karşı direnç kaybı görülebilir. ${ }^{[9]}$ Dislokasyon varlığı durumlarında da, muayene esnasında eversiyon ve aktif dorsifleksiyonla provokasyon yapılabilir.

\section{TEŞHiS}

Peroneal tendon yaralanmalarında tanıya ulaşmadaki en önemli kriterler öykü ve fizik muayenedir. Yapılması planlanan diğer tetkikler, çoğunlukla diğer olası durumların dışlanması için gereklidir.

Kemik çıkıntısı, os peroneum kırığı, kalsifikasyon benzeri durumlar, akut ya da kronik kırık gibi durumların dışlanması için, basarak anteroposterior ve lateral grafiler çekilmelidir. 


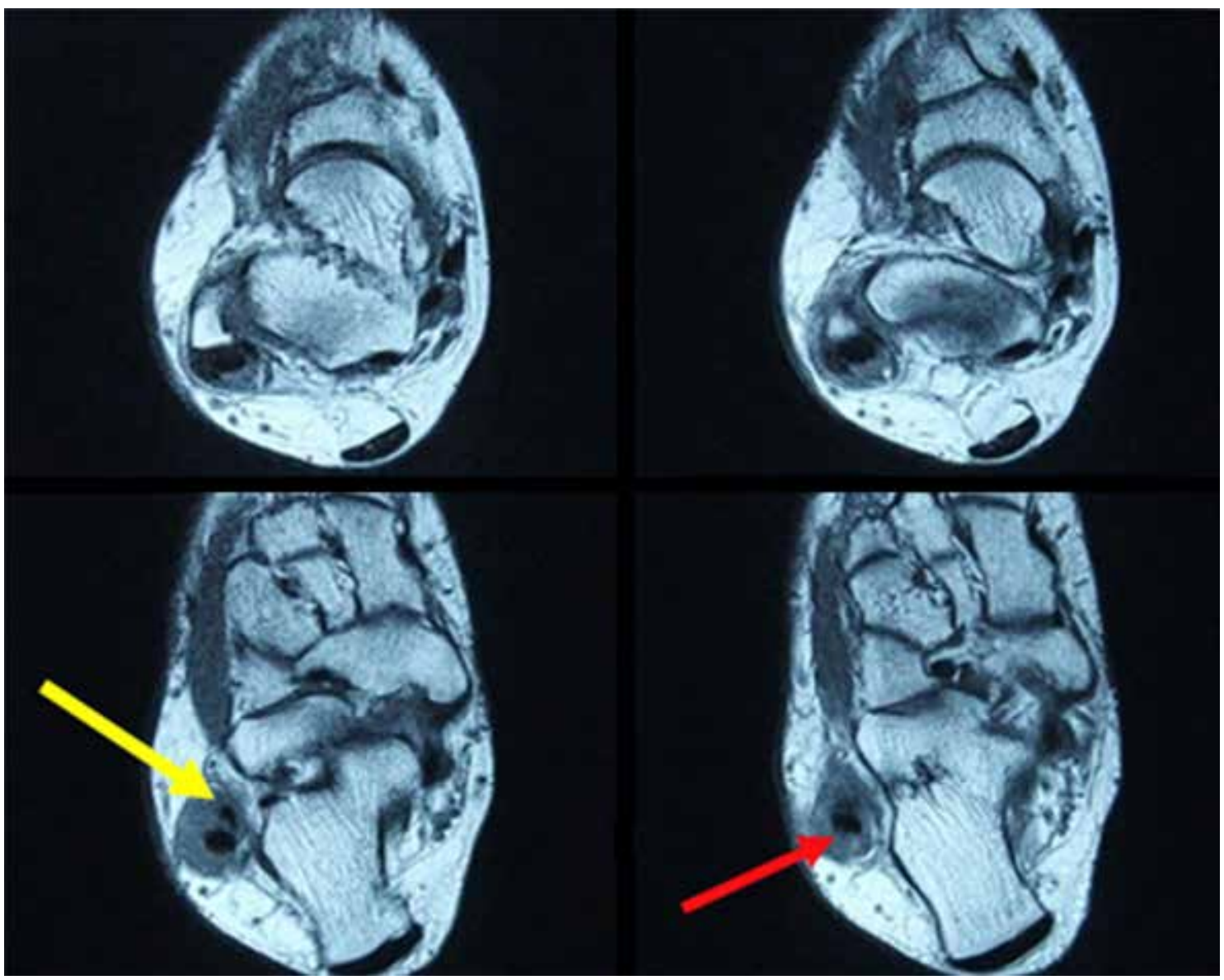

Şekil 5. Peroneus breviste yırtık (sarı ok) ve peroneus longusta hipertrofi (kırmızı ok).

Peroneal tendon ve peroneal tendonların çevresindeki yapıların değerlendirilmesi için MR görüntüleme kullanılır (Şekil 5). Yapılan çalışmalarda, MR'nin peroneal tendinopatilerdeki sensitivite (\%84-90) ve spesifisitesi (\%72-75) farklı oranlarda bildirilmiştir. ${ }^{[10,11]}$

Ultrasonografi (US)'nin MR görüntüleme ile kıyaslandığında birçok avantajı vardır. Daha ekonomik olmasının yanı sıra, ayaktan gelen hastalara fizik muayene sırasında dahi uygulanabilir. US, tendonların da dinamik olarak değerlendirilmesine firsat verir ki bu özelliği de periyodik dislokasyon ve subluksasyon gibi MR'de görüntülenmesi zor olan dinamik durumların değerlendirilmesini sağlar. Tendon çevresi ve tendon kılıfı içindeki sıvı, tendondaki kalınlaşmalar, rüptürler ve fibula tipi çevresindeki luksasyonlar US'de değerlendirilebilir. ${ }^{\left[{ }^{[8]}\right.}$ Fakat, US cihazının kalitesiyle gözlem kalitesinin birbirine paralel seyrettiği unutulmamalıdır.

Özellikle kalkaneus kırıkları sonrasında lateral duvarda görülebilen patolojiler, retromalleolar oluğun değerlendirilmesi, peroneal tüberkülde görülebilen hipertrofiler (Şekil 6) gibi kemik patolojilerinin değerlendirilmesi için bilgisayarlı tomografi (BT) en iyi yöntemdir. ${ }^{[12]}$

Illk kez van Dijk ve Kort tarafindan tanımlanan peroneal tendoskopi, peroneal tendon yaralanmalarının tanısında kullanılmaya başlamıştır. ${ }^{[13]}$ Önce fibula tipinin $2 \mathrm{~cm}$ distaline tendonla aynı hizada distal portal açılır. Proksimal portal ise, tendon kilıfina salin insuflasyonu sonrası, fibula tipinin $3 \mathrm{~cm}$ proksimaline açılır. BT, prensip olarak tanı için kullanılsa da, basit tenosinoviyektomi ve yapışıklıkların açılması için de kullanılabilir. ${ }^{[2]}$

\section{PERONEUS BREVIS YARALANMALARI}

Peroneus brevis tendon patolojileri, tendinitten tenosinovit ve yırtığa kadar değişkenlik gösterebilir. Mekanik faktörler, postüral nedenler ve travma esas sorumlu nedenlerdir. Bunlara bağlı olarak; tendonun kalınlaşması ve rüptürü ile sonuçlanabilecek tendon tendon kılıfı akut inflamasyonu başlayabilir (Şekil 7). 


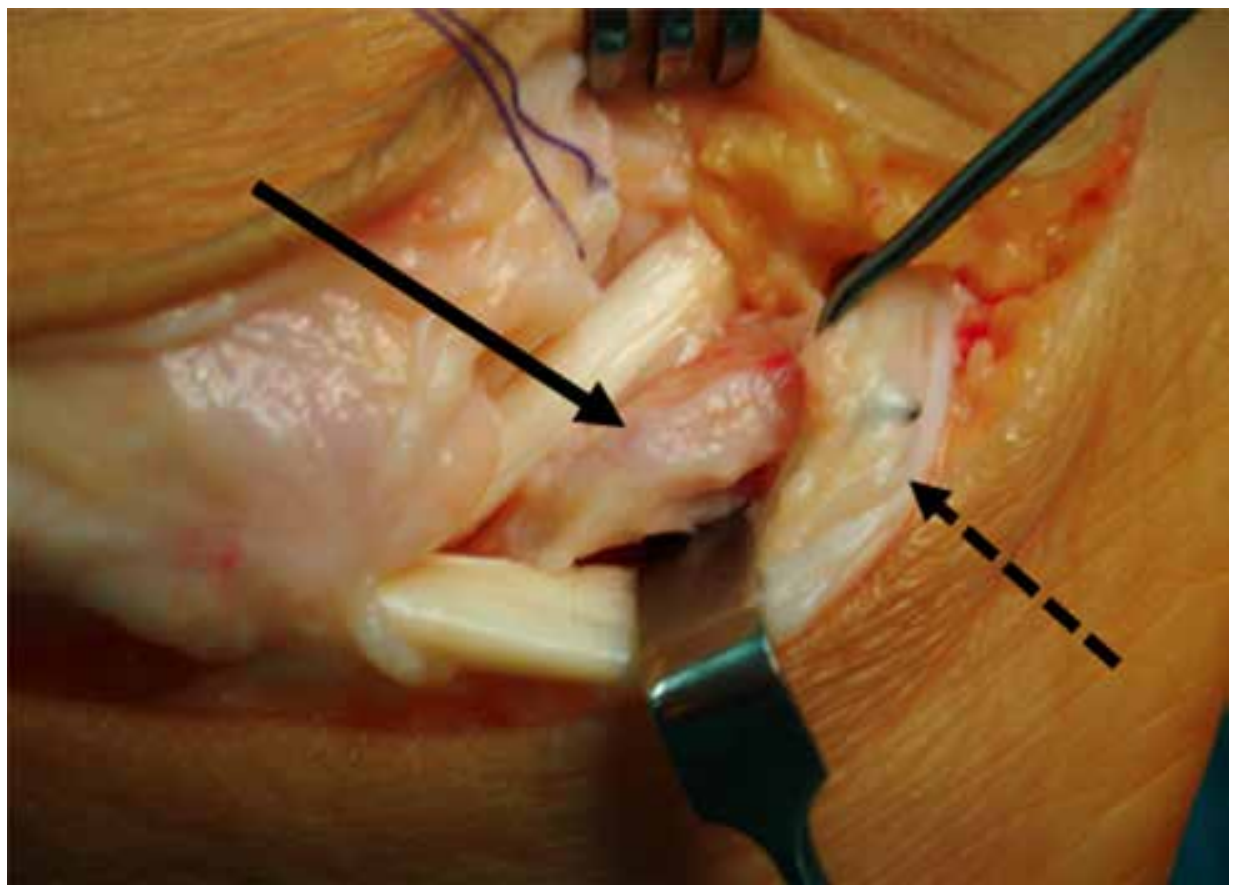

Şekil 6. Hipertrofik peroneal tüberkül (siyah, devamlı ok) ve peroneus longusta yırtık (siyah, kesik çizgili ok).

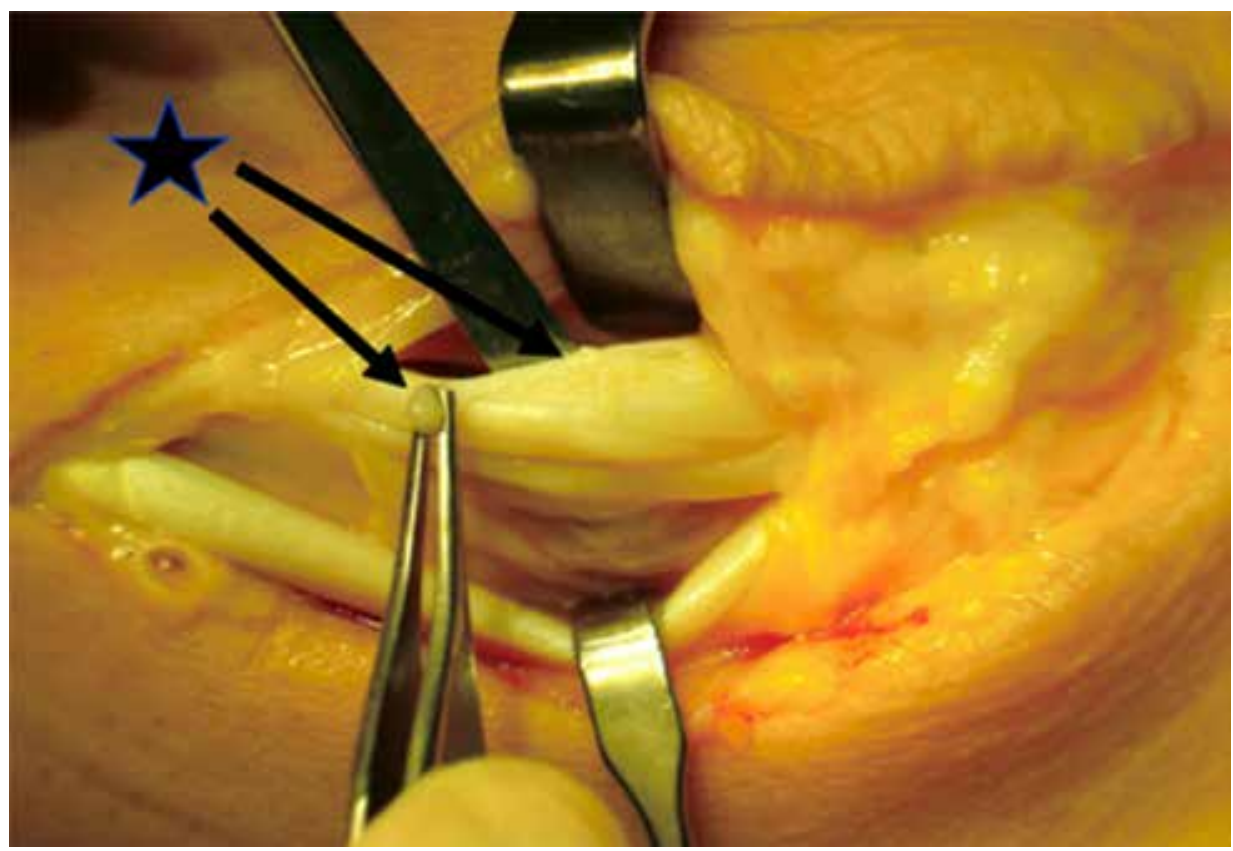

Şekil 7. Peroneus breviste yırtık (siyah oklar).

Peroneus brevis tendonu, peroneus longus tendonu ile fibulanın posterior yüzü arasında uzanır. Her iki tendonun da fibula tipinden yapışma noktalarına doğru keskin dönüş yaptıkları yerde, peroneus breviste aşınmaya neden olan ciddi bir basınç etki eder. Kadavra çalışmalarında, peroneus brevis yaralanmalarının bu alanda olduğu gösterilmiş̧tir. ${ }^{[14]}$

Ek anatomik faktörler de peroneus breviste mekanik aşınmaya neden olabilir. Peroneus brevis kasının muskülotendinöz bileşkesinin uzun olmasından dolayı 
distale uzanan peroneus brevis kası durumunda, tendon kılıfının dolmasından dolayı ve peroneus kuartus durumlarında, mekanik aşınmalar söz konusu olabilir. Peroneus kuartus varlığında, peroneus brevis yırtığı riski normale göre iki kattır. ${ }^{[6,14,15]}$

Peroneal patolojilerin erken safhalarında akut inflamasyon bulguları görülse de, peroneus brevisin yırtıklarında yapılan histolojik incelemede tendonun kendisinde inflamasyona ait bulgular görülmemiştir. Bunun yerine, kollajen liflerinde yayılma ve damar ile fibrovasküler bağ dokusunda proliferasyon saptanmıştır. Bu durum, peroneus brevis yırtıklarındaki birincil nedenin mekanik olduğunu; kronik inflamasyona bağlı gelişen dejenerasyona bağlı gelişmediğini gösterebilir.[16]

Ardayak varusu gibi duruş bozuklukları peroneal tenopati nedeni olabilir. Ardayak varusu, peroneus longus ve brevis tendonlarına aktarılan kurveti belirgin oranda arttırır. Lateral ayak bileği bağ instabilitesine bağlı sık ayak bileği burkulması görülen hastalarda, peroneus brevis yırtığı görülme sıklığı artış gösterir. Kronik lateral ayak bileği instabilitesi olan ve bu nedenle bağ rekonstrüksiyonu uygulanan 61 hasta ile yapılan bir çalışmada; hastaların \%77'sinde peroneal tenosinovit ve \%25'inde peroneus brevis yırtığı, \%54'ünde peroneal retinakulumda zayıflama ve \%49'unda ayak bileğinde sinovit saptandığı bildirilmiştir. ${ }^{[17]}$ Bir başka travma mekanizması ise, yetersiz SPR'ye bağlı olarak gelişen peroneal tendon subluksasyonu ya da dislokasyonudur. Fibulanın keskin posterolateral köşesi, üstüne binmiş olan peroneus breviste longitudinal ayrışmalar oluşturabilir. SPR'nin intakt olduğu fakat yine de subluksasyonun görüldüğü durumların da peroneus breviste longitudinal yırtıklar oluşturabileceği bildirilmiştir. ${ }^{[18]}$

\section{PERONEUS BREVIS YARALANMALARININ TEDAVisi}

Peroneus brevis ve longus tendonlarının konservatif tedavileri benzerdir. Tendonlar subtalar eklemin lateralinde seyrettiği için, tekrarlayan arka ayak inversiyonu ile tendonlar gerilir; bu nedenle, ağrı ve inflamasyon oluşur. Ayak bileğinin breys ya da atel ile immobilize edilmesi bu hareketleri kısıtladığı için, semptomatik rahatlama sağlanır ve tendonların kendini onarmasına olanak tanınır. Topuğu valgus pozisyonunda tutan lateral destekli ayakkabılar da, her iki peroneal tendonu ve tendon kılıfını rahatlattığı için, konservatif tedavide kullanılabilir.

Non-steroid anti-inflamatuvar ilaçlar (NSAii), kriyoterapi ve istirahat gibi standart ortopedik müdahaleler, şikayetleri yatıştırmak için yararlı olabilir. Fizik tedavi ile, zayıflamış olan peroneus longus ya da brevis kası güçlendirilebilir. Fakat, konservatif tedavi ile başarısızlık oranının çok yükssek olduğu bir gerçektir. ${ }^{[2]}$

Peroneus brevisin cerrahi tedavisi, basit bir tenosinoviyektomiden distalde seyreden peroneus brevisin kaslı şişkin kısmının ya da aksesuvar kasın debridmanına ve yırtılmış bir tendonun debridmanı ya da onarılmasından peroneus longusa tenodezi veya tendon transferine kadar çok geniş bir yelpazede değerlendirilmelidir.

$\mathrm{Bu}$ operasyonların her biri için cerrahi yaklaşım aynıdır. Hasta, lateral dekubit pozisyonunda hazırlanır ve fibulanın hemen posteriorundan, tendonların hemen üzerinden yapılan kavisli (curved) insizyon uygulanır. İnsizyonun uzunluğu, hastaya ve şikayetlerine yönelik değişkenlik gösterebilir. Peroneal retinakulumu ortaya koymak için, süral sinire dikkat edilerek subkutan disseksiyon yapılır. Tüm peroneal tendon cerrahilerinde, tendonların ortaya konulması için SPR'nin açılması en kritik aşamalardan birini oluşturur. Eğer SPR'nin açılması esnasında insizyon fibulanın posteriorunda çok anteriordan yapılırsa, prosedürün sonunda SPR'nin tamiri için yeterli SPR posterior flebi kalmayacaktır. SPR insizyonu çok anteriordan yapıldığında ise, eğer oluk derinleştirme operasyonu uygulanmışsa, bu kez retinakulumun tamiri mümkün dahi olmayabilir. ${ }^{[2]}$

Öncelikli olarak tendonlar ortaya konulur ki, genellikle tendonların etrafı sarı proliferatif sinovit dokusu ile çevrilidir. Bu dokular tendonlardan debride edilir ve bu aşamada, sonra onarılması elzem olan SPR'nin korunması için dikkatli olunmalıdır. Eğer peroneus breviste distal seyirli kas şişliği mevcutsa, bu doku kılıfın dekomprese edilmesi için eksize edilmelidir. Yine aynı şekilde, peroneus kuartus aksesuvar kası mevcutsa, bu da eksize edilmelidir. Ardından, tendonlar yırtık açısından değerlendirilip gözden geçirilir. Her iki tendonun da, hem derin hem de yüzeyel kısımlarının longitudinal yırtıklar açısından ya da fuziform genişlemeler açısından dikkatlice gözden geçirilmesi oldukça önemlidir. Eğer peroneus brevise ait bir yırtık saptanırsa, tamir ya da eksizyon arasında bir karar verilmelidir. Krause ve Brodsky, \%50'den fazla intakt kesitsel alanın olduğu Grade 1 yırtıklarda, hasarlı tendonun debridmanını ve geri kalan intakt peroneus brevisin tübülarizasyonunu önermişlerdir. Teorik olarak, peroneus brevisin \%50'sinin feda edildiği anatomik olmayan bağ rekonstrüksiyonlarıyla gösterildiği gibi, bu tamirden sonra minimal fonksiyonel defisit kalmalıdır. Kesitsel alanın \%50'den fazla yırtık ve iş göremez durumda olduğu Grade 2 yaralanmalar için, hasarlı tendonun eksize edilip peroneus longusa tenodezi önerilmiştir. ${ }^{[19]}$ Peroneus brevisin eversiyona katkıda bulunabilmesi için, tüm olgularda tenodez 
işlemi yırtığın proksimaline yapılmalıdır. Yırtığın distaline tenodez işlemi, sadece distal tendonun sağlıklı olduğu durumlarda yapılmalıdır. ${ }^{[20]}$

Peroneal tendon cerrahisi esnasında sık karşılaşılan üç durum söz konusudur. Birincisi, longitudinal yırtığın tendonun bir tarafında olduğu ve diğer tarafa uzanmadığı yırtıklardır. Parsiyel yırtıklarda, tendonun iç kısmı tendinozis ve yırtık parçalardan debride edilir ve her iki taraf side to side şeklinde ve 4-0 continue dikiş tekniği ile onarılır. İkincisi ise, split şeklindeki yırtığın direkt ortada uzandığı ve tendonu makul bir şekilde ortadan ikiye böldüğü yırtıklardır. Bu durumlarda, tendonun bir kısmını feda etme ya da her iki tarafı onarıp iyileşmesini bekleme kararı cerraha bırakılmıştır. Son olarak, bazı olgularda tendonda fuziform kalınlaşma ve genişleme olduğu, yırtığın görülmediği durumlar söz konusudur. Eğer cerrahi öncesi muayenede ağrının primer kaynağının bu bölge olduğu düşünülüyorsa, tendon longitudinal olarak açılır, tendinozis debride edilir ve tendonun kesilen iki tarafı continue olarak 4-0 dikiş ile sütüre edilir. ${ }^{[2]}$

Eğer tam kat transvers bir yırtık söz konusu ise, peroneus brevisin distali peroneus longusa tenodez edilmelidir. Böylece, peroneus longusun arka ayağa eversiyon yaptırma etkisi biyomekanik olarak daha avantajlı bir şekilde olacaktır. Eğer yırtık yeni ise ve hala yeterli peroneus brevis artığı varsa, ardayak eversiyon gücünü arttırmak için proksimal bitiş de longusa tenodez edilmelidir. ${ }^{[21]}$

Peroneus longus ve brevis kaslarının kopuk ve kullanılamaz durumda olduğu kronik durumlarda, tendonlar eksize edilir ve sağlıklı kas dokusu ile distal tendon arasına allogreft interpoze edilebilir. Eğer proksimal kas dokusu kontrakte olmuş ve zayıf ise, fleksör dijitorum longus veya fleksör hallusis longus tendon transferi daha iyi olacaktır. ${ }^{[2]}$

Peroneal tendon yırtıklarına eşlik eden birçok patoloji söz konusu olabilir ve tedavi esnasında bu patolojiler düzeltilmezse, başarısızlık ya da rekürrens ile sonuçlanabilir. Ayak bileği instabilitesinin eşlik ettiği durumlar, Brostrom-Gould prosedürü ile ya da yırtık varsa peroneus brevis tendonunun yarısı alınarak uygulanabilecek anatomik olmayan tamirler ile tedavi edilebilir. Ardayak varusunun eşlik ettiği durumlarda, tendon tamiri üzerindeki gerginliği azaltmak için kalkaneal osteotomi yapılabilir. ${ }^{[20]}$ Peroneal tendon subluksasyonu, SPR'nin büzülmesi ya da oluk derinleştirme prosedürleri ile giderilebilir. Tüm bu prosedürler esnasında SPR'nin dikkatli ve titiz bir şekilde onarılması, cerrahi sonrası tendon subluksasyonunun önlenmesi için önemlidir. Pasif hareketlerle erken rehabilitasyon, tendonların ağrılı skar oluşturarak iyileşmesini önleyen önemli etkenlerdendir.

\section{PERONEUS LONGUS YARALANMALARI}

Peroneus longus yaralanmaları peroneus brevise oranla daha az sıklıkta görülür ve sıklıkla daha çok strese maruz kalınan, beslenmenin daha az olduğu alanlar olan fibula tipi, peroneal tüberkül ve küboid çentik seviyesinde meydana gelir. Yapılan bir çalışma$\mathrm{da}$, peroneus longus tendinopatisi görülen hastaların $\% 82$ 'sinde ardayak varusu olduğu ve bu hastaların \%33'ünde peroneus brevis patolojisinin de olduğu ortaya konmuştur. ${ }^{[22]}$

\section{Ağrılı Os Peroneum Sendromu (AOPS)}

Peroneus longus tendonu yaralanmaları ile ilişkili durumları ifade eder ve peroneus longus tenosinoviti, peroneus longus yırtığı, büyümüş peroneal tüberkül ve os peroneum kırığını içerir. Bunların hepsi peroneus longus trasesi boyunca, fibula tipinden küboid çentiğe kadar lateral ardayak ağrısı nedeni olabilir. ${ }^{[23]}$

Tenosinovit genellikle her iki tendonun ortak kılıfını ilgilendirir ve distale, tendonların kendi kılıfına doğru uzanabilir. Yırtık ya da distalde seyreden kas şişliği olabilir ya da olmayabilir. Peroneus longusun yırtıkları, basit longitudinal bir yırtıktan, os peroneumun proksimali ya da distalinde yerleşen komplet bir yırtığa kadar değişkenlik gösterebilir. Altta yatan bir kemik patolojisi, örneğin büyük bir peroneal tüberkül, bası altında kalmaya bağı tenosinovitin veya sıkışmanın nedeni olabilir (Şekil 6). ${ }^{[2]}$

Os peroneumun kırı̆̆ı AOPS'ta son parametreyi oluşturur. Bu kemik, peroneus longusun içinde yer alan fibrokartilajinöz bir sesamoid kemiktir ve tendonun plantar orta ayağa doğru geçerken keskin bir dönüş yaptığı yer olan küboid çentik ile eklem yapar. Hastaların \%20'sinde ossifiyedir ve \%10-20 oranında küboid kemiğin plantarinde, kalkaneoküboid eklemin komşuluğunda bulunur. Os peroneum kırığı, direkt darbe ile ya da supinasyon pozisyonundaki ayağın güçlü eversiyona maruz kalmasıyla oluşabilir. ${ }^{[23]}$

\section{PERONEUS LONGUS YARALANMALARININ TEDAVisi}

Peroneus brevis ve longus tendonlarının konservatif tedavileri benzerdir. Peroneus longusun cerrahisinde, genellikle os peroneum ve peroneal tüberkülü ortaya koymak için cilt insizyonunun tendon trasesi boyunca distale doğru uzatılması gerekir. Süral sinire ait dallar, bu bölgede yaralanma açısından risk altındadır ve ortaya konulup ekarte edilmelidir. Tenosinovit debride edilip, aksesuvar kaslar ve distale uzanan kas şişliği mevcutsa eksize edilip, tendon dekomprese edilmelidir. Tendon boyunca derin ve yüzeyel kısımlar 
dikkatli bir şekilde muayene edilmeli ve olası yırtık ve nodüler bir kalınlaşma açısından değerlendirilmelidir. Longitudinal yırtıklar 4-0 continue sütür ile onarılmalıdır. Tendinozis açılmalı ve tendonun dejenere kısmı debride edilmelidir. Tam yırtık ya da çok az kurtarılabilir sağlam tendon mevcutsa, peroneus brevise tenodez uygun olabilir. Nadir de olsa, peroneus longusun os peroneum distalinde rüptürü söz konusu olabilir ve bu durumlarda direkt tamir uygulanabilir. ${ }^{[21]}$

Os peroneum kırığı genellikle operasyon öncesinde saptanır. Os peroneuma ait parçalar subperiostal olarak eksize edilmeli ve tendonun esas iskeleti absorbe edilemeyen sütürler ile kuvvetlendirilmelidir. Yapılan muayenelerde (cerrahi öncesi ya da sırasında) peroneal tüberkülün büyümüş olduğu görülürse, her iki tendonun kılıfı açılır ve tendonlar dekomprese edilir. Peroneal tüberkülün de subperiostal açılmasını takiben, ekzosteoektomi uygulanıp peroneus longusun irrite olması engellenmiş olur. Kansellöz kemiğin kanamasıyla oluşabilecek yapışmaları önlemek için bone wax kullanılabilir. ${ }^{[2]}$

\section{PERONEAL TENDON SUBLUKSASYON VE DISLOKASYONLARI}

Peroneal tendon dislokasyonu, sıklıkla spor yaralanmalarını takiben, özellikle kayak sonrası meydana gelir (Şekil 8 ve Şekil 9). Aynı zamanda, buz pateni, futbol, basketbol, rugby ve jimnastik sonrası da sıklıkla görülür. Olguların çoğunun (\%92) bir travma sonrası geliştiği düşünülür. ${ }^{[24]}$ Eklem içi kalkaneus kırıklarının da \%42'si peroneal tendon dislokasyonu ile ilişkilidir. ${ }^{[25]}$

Peroneal tendon dislokasyonu olan hastalar, sıklıkla ağrı ve ayak bileğinin posterolateralinde şişlikten yakınırlar; malleolün arkasında sıklıkla duyulabilen ve görülebilen bir atlama ve "popping" tarif ederler.

Peroneal tendonun subluksasyon ya da dislokasyonu, SPR'nin yaralanmasıyla, sığ ya da konveks şekilli fibular oluk varlığında, genel ligamentöz laksite ve topuk varusu durumlarında görülebilir. SPR, peroneal dislokasyonun en önemli önleyicisidir. Bağ, fibulanın posterior inferior köşesinden başlayarak kalkaneus veya Aşil tendon kılıfı olmak üzere farklı bölgelere yapışır. SPR en sık güçlü ayak bileği dorsifleksiyonu, arka ayak inversiyonu esnasında peroneallerin kasılması mekanizması ile yırtılır.

1976'da yapılan bir çalışmada, SPR hasarı olan 73 hasta değerlendirilmiş ve üç sınıfa ayrılmıştır. Bunların \%51'lik kısmını oluşturan, SPR'nin lateral malleolden avülsiye olduğu Grade 1 yaralanmalarda, tendon kemikle periost arasında uzanım gösterir. Diğer \%33'lük kısımda görülen Grade 2 yaralanmalarda, fibrokartilaj boşluk retinakulumla birlikte avulsiye olmuştur ve tendon fibrokartilaj boşluk ile fibula arasındadır. Geriye kalan \%16'lık bölümünü oluşturan Grade 3 yaralanmalarda ise, ince bir kortikal parça fibuladan avulsiye olmuştur. ${ }^{[26]}$ Bu sınıflama sistemine, 1987 yılında Odden tarafından, SPR'nin posterior yapışma yeri olan kalkaneus ve Aşil tendonunun derin fasya bağlantısından koptuğu, tendonun peroneal retinakulumun yüzeyelinde seyrettiği Grade 4 yaralanmalar eklenmiştir.[27]

\section{PERONEAL TENDON SUBLUKSASYON VE DISLOKASYONLARININ TEDAVISI}

Grade 3 peroneal dislokasyonlar, kısa bacak alçı-atel immobilizasyonu ile tedavi edilebilir. ${ }^{[12]}$ Fakat, diğer gruplar için bildirilmiş başarı oranları düşüktür (\%26$57)$ ve genellikle cerrahi gerekir. ${ }^{[28]}$

\section{Superior Peroneal Retinakulumun Direkt Onarımı}

Peroneal tendonlar ile aynı trasede, fibulanın $1 \mathrm{~cm}$ posteriorundan fibula tipinin $4 \mathrm{~cm}$ proksimalinden başlayıp $2 \mathrm{~cm}$ distaline kadar uzanan insizyon yapılır. Süral sinir korunarak SPR longitudinal olarak açılır. Tendonlar yırtık ve tenosinovit açısından değerlendirilir ve uygun işlemler yapılır. Fibrokartilaj boşluk feda edilir ve SPR retromalleolar oluğa transosseöz sütür ya da ankor kullanılarak dikilir. Bu işlem esnasında, tendonun yerine yerleşmesi için ve hareket edebilmesine izin verecek yeterli gerginlik ayarlanır ve ardından insizyon hattı boyunca büzülerek kapatılır. ${ }^{[12]}$

\section{Kronik Dislokasyon}

SPR'nin tedavisinin temeli olarak, birçok yumuşak doku ve kemik operasyonlarını içeren teknikler bildirilmiştir.

\section{Direkt Onarım}

Kronik hasarlı SPR, akut hasarlı SPR'ye oranla daha az kullanılabilir durumdadır. Anterior retinakular flep, posterior flep üzerine iki kez geçilerek dikilir.

\section{Retromalleolar Oluk Derinleştirme}

Hem direkt hem de indirekt onarım teknikleri tanımlanmıştır. Direkt metodda, retromalleolar oluğun kartilajinöz katmanı kaldırılıp kansellöz kemik ortaya konulur. Ardından, tendonun rahatlıkla hareket etmesine izin verecek şekilde kürete edilir ya da burr ile derinleştirilir. Oluğun tabanı yerleştirilip sıkıştırılır ve tendonlar yerleştirilip SPR onarılır. ${ }^{[12]}$ 


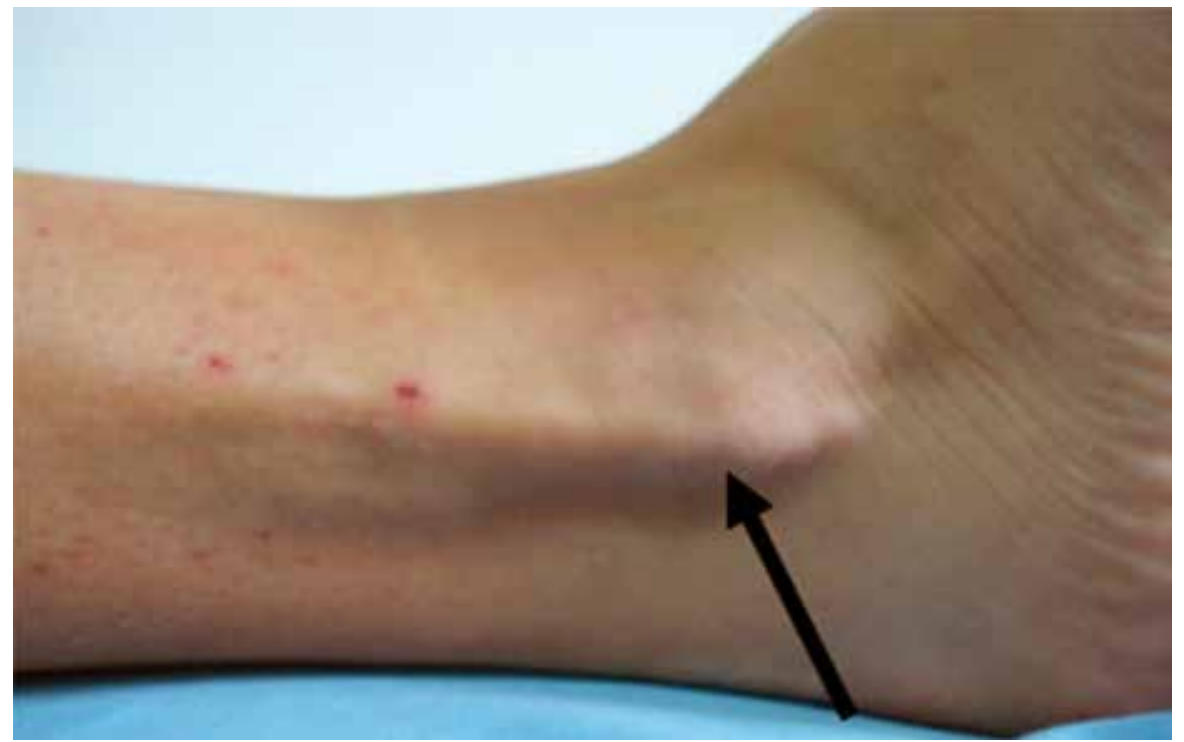

Şekil 8. Peroneal tendonları sublukse bir olgu (siyah ok, sublukse peroneal tendon).
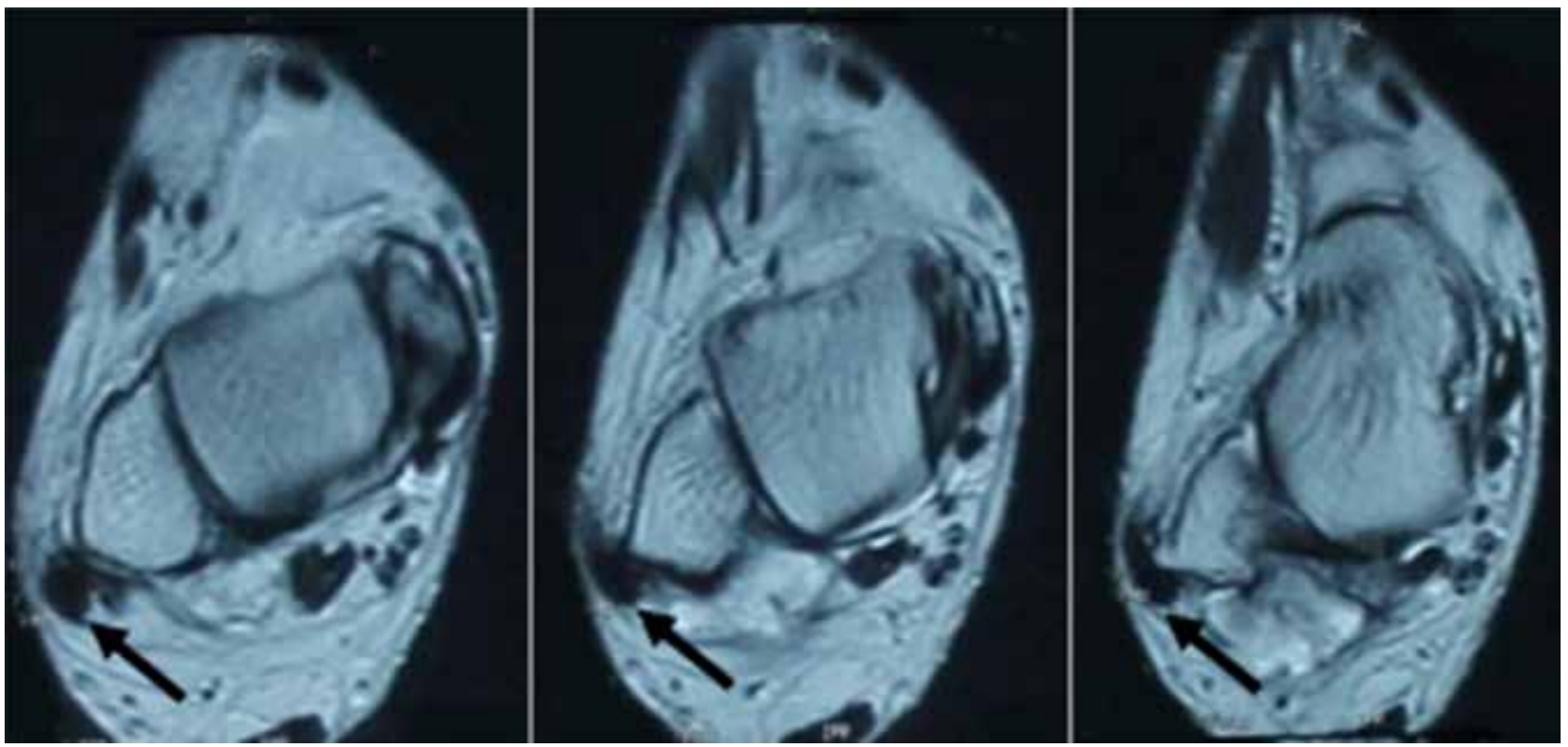

Şekil 9. Sublukse peroneal tendonların MR görüntüsü (siyah oklar, sublukse tendon).

\section{Tendon Grefti ile Rekonstrüksiyon}

SPR'nin kuvvetlendirilmesi için açılan transosseöz fibular tüneller üzerinden Aşil ve plantaris tendonlarını kullanarak tarif edilmiş ve çeşitli başarı oranlarına sahip teknikler vardır.

\section{Kemik Blok Prosedürleri}

Sagittal planda yapılan bir osteotomiyi takiben, distal fibula döndürülerek ya da posteriora kaydırılarak peroneal dislokasyona fiziki bir engel oluşturulur.

\section{Tendon Re-Routing -Kılıf İçi Subluksasyon}

Retinakulum intakt iken peroneus brevis ve longusun birbirleri üzerinde çapraz yapmasıyla meydana gelir. Hastalarda ağrı ve sirkumdiksiyon esnasında atlama hissi olur.

\section{AMELIYAT SONRASI BAKIM VE REHABILITASYON}

Çoğu cerrahi müdahale sonrası, eklem hareket açıklığı egzersizlerine başlanmadan önce 4-6 hafta 
alçı-atel ile immobilizasyon uygulanır. Öncelikli olarak atel çıkarılır; aktif, aktif asiste ve pasif hareketlere; özellikle pasif inversiyon ve aktif eversiyon hareketlerine daha dikkat edilerek başlanır. Koltuk değneği ile basarak mobilizasyon, tolere edilebildiğince yavaş yavaş arttırılır. Düşük ağırlıklar ile dirence karşı ayak bileği egzersizleri ve erken dönemde sık tekrarlar ile, ayak bileği kaslarının dayanıklılığı restore edilir. Denge ve propriyosepsiyon egzersizleri, alçı-atel çıkarıldıktan sonra başlanıp, yavaş yavaş daha zor aktivitelere doğru arttırılabilir. ${ }^{[29]}$

\section{SPORA DÖNÜŞ}

Anatomik yapılar, tüm ayak bileği hareketleri için kritik bir role sahiptir ve bundan dolayı cerrahi onarım sonrası spora dönüş altı ayı bulacaktır. Eğer longitudinal split bir yırtık onarıldıysa, skar dokusu oluşumunu minimize etmek için, başlanacak eklem hareket açıklığı egzersizleri ile üç ay boyunca onarımın korunması gerekir. Allogreft rekonstrüksiyonu ya da tenodez uygulanan bir hastada, spora dönüş için altı aylık bir süre gerekli olacaktır. Oluk derinleştirme operasyonları sonrası ise, Braström prosedürüne benzer şekilde, spora dönüş için beş aylık bir süre gerekecektir. ${ }^{[29]}$

\section{KAYNAKLAR}

1. Petersen W, Bobka T, Stein V, Tillmann B. Blood supply of the peroneal tendons: injection and immunohistochemical studies of cadaver tendons. Acta Orthop Scand 2000;71(2):168-74. Crossref

2. Jeng C. Peroneal Tendon Disorders. In: Altchek DW, DiGiovanni CW, Dines JS, Positano RG, editors. Foot and Ankle Sports Medicine. Wolters Kluwer, Lippincott Williams \& Wilkins; 2013. pp.141-9.

3. Clarke HD, Kitaoka HB, Ehman RL. Peroneal tendon injuries. Foot Ankle Int 1998;19(5):280-8. Crossref

4. Rademaker J, Rosenberg ZS, Beltran J, Colon E. Alterations in the distal extension of the musculus peroneus brevis with foot movement. AJR Am J Roentgenol 1997;168(3):787-9. Crossref

5. Bilgili MG, Kaynak G, Botanlioğlu H, Basaran SH, Ercin E, Baca E, Uzun I. Peroneus quartus: prevalance and clinical importance. Arch Orthop Trauma Surg 2014;134(4):481-7. Crossref

6. Zammit J, Singh D. The peroneus quartus muscle. Anatomy and clinical relevance. J Bone Joint Surg Br 2003;85(8):1134-7.

7. Wang XT, Rosenberg ZS, Mechlin MB, Schweitzer ME. Normal variants and diseases of the peroneal tendons and superior peroneal retinaculum: MR imaging features. Radiographics 2005;25(3):587-602. Crossref

8. van Dijk PAD, van Dijk CN. Peroneal Tendons. In: Canata GL, d'Hooghe P, Hunt KJ, editors. Muscle and Tendon Injuries -Evaluation and Management. Berlin Heidelberg: Springer; 2017. pp.373-80.

9. Sammarco GJ, DiRaimondo CV. Chronic peroneus brevis tendon lesions. Foot Ankle 1989;9(4):163-70.
10. Kennedy JG, van Dijk PA, Murawski CD, Duke G, Newman H, DiGiovanni CW, Yasui Y. Functional outcomes after peroneal tendoscopy in the treatment of peroneal tendon disorders. Knee Surg Sports Traumatol Arthrosc 2016;24(4):1148-54. Crossref

11. Park HJ, Cha SD, Kim HS, Chung ST, Park NH, Yoo JH, Park $\mathrm{JH}$, Kim JH, Lee TW, Lee CH, Oh SM. Reliability of MRI findings of peroneal tendinopathy in patients with lateral chronic ankle instability. Clin Orthop Surg 2010;2(4):23743. Crossref

12. Davda K, Malhotra K, O'Donnell P, Singh D, Cullen N. Peroneal tendon disorders. EFORT Open Rev 2017;2(6):28192. Crossref

13. van dijk $\mathrm{CN}$, Kort $\mathrm{N}$. Tendoscopy of the peroneal tendons. Arthroscopy 1998;14(5):471-8.

14. Sobel M, Bohne WH, Levy ME. Longitudinal attrition of the peroneus brevis tendon in the fibular groove: an anatomic study. Foot Ankle 1990;11(3):124-8.

15. Sobel M, Levy ME, Bohne $\mathrm{WH}$. Congenital variations of the peroneus quartus muscle: an anatomic study. Foot Ankle 1990;11(2):81-9.

16. Sobel M, DiCarlo EF, Bohne WH, Collins L. Longitudinal splitting of the peroneus brevis tendon: an anatomic and histologic study of cadaveric material. Foot Ankle 1991;12(3):165-70.

17. DiGiovanni BF, Fraga CJ, Cohen BE, Shereff MJ. Associated injuries found in chronic lateral ankle instability. Foot Ankle Int 2000;21(10):809-15. Crossref

18. Raikin SM, Elias I, Nazarian LN. Intrasheath subluxation of the peroneal tendons. J Bone Joint Surg Am 2008;90(5):9929. Crossref

19. Krause JO, Brodsky JW. Peroneus brevis tendon tears: pathophysiology, surgical recon- struction, and clinical results. Foot Ankle Int 1998;19(5):271-9. Crossref

20. Redfern D, Myerson M. The management of concomitant tears of the peroneus longus and brevis tendons. Foot Ankle Int 2004;25(10):695-707. Crossref

21. Slater HK. Acute peroneal tendon tears. Foot Ankle Clin 2007;12(4):659-74. Crossref

22. Brandes CB, Smith RW. Characterization of patients with primary peroneus longus tendinopathy: a review of twentytwo cases. Foot Ankle Int 2000;21(6):462-8. Crossref

23. Sobel M, Pavlov H, Geppert MJ, Thompson FM, DiCarlo $\mathrm{EF}$, Davis WH. Painful os peroneum syndrome: a spectrum of conditions responsible for plantar lateral foot pain. Foot Ankle Int 1994;15(3):112-24. Crossref

24. Clanton TO. Athletic injuries to the soft tissues of the foot and ankle. In: Cuoghlin MJ, Mann RA, editors. Surgery of the Foot and Ankle, 7th ed. St Louis: Mosby; 1999. pp.1090-209.

25. Ebraheim NA, Zeiss J, Skie MC, Jackson WT. Radiological evaluation of peroneal tendon pathology associated with calcaneal fractures. J Orthop Trauma 1991;5(3):365-9.

26. Eckert WR, Davis EA Jr. Acute rupture of the peroneal retinaculum. J Bone Joint Surg Am 1976;58(5):670-2.

27. Oden RR. Tendon injuries about the ankle resulting from skiing. Clin Orthop Relat Res 1987;(216):63-9.

28. Selmani E, Gjata V, Gjika E. Current concepts review: peroneal tendon disorders. Foot Ankle Int 2006;27(3):221-8. Crossref

29. Park JS. Peroneal Tendon Surgery, Chapter 7 , Ankle and Foot. In: Miller MD, Chhabra AB, Konin J, Mistry D, editors. Sports Medicine Conditions Return to Play: Recognition, Treatment, Planning. Wolters Kluwer, Lippincott Williams \& Wilkins; 2014. pp.236-7. 